Gut, 1981, 22, 203-206

\title{
Prospective study of periostitis and finger clubbing in primary biliary cirrhosis and other forms of chronic liver disease
}

\author{
O EPSTEIN, R DICK, AND S SHERLOCK
}

From the Academic Department of Medicine and Department of Radiology, Royal Free Hospital, London

SUMMARY The association of finger clubbing and periostitis has been reported in primary biliary cirrhosis and, more rarely, in other forms of chronic liver disease. The prevalence of periostitis and its relationship to finger clubbing is unknown. In this prospective study, we have determined the prevalence of periostitis and finger clubbing in 74 patients with primary biliary cirrhosis and 54 with other forms of chronic liver disease. Clubbing was present in $24 \%$ of patients with primary biliary cirrhosis, $29 \%$ with HBsAg negative chronic active hepatitis, and $23 \%$ in the group of miscellaneous liver diseases. Symmetrical periostitis affecting the tibiae and fibulae occurred in $35 \%$ of patients with primary biliary cirrhosis, $29 \%$ with chronic, active hepatitis and $40 \%$ of patients in the miscellaneous group. The distal radii and ulnae were affected in only eight patients $(6 \%)$. In primary biliary cirrhosis, the presence of finger clubbing was strongly associated with periostitis $(\mathrm{P}<0.01)$. but this association was uncommon in other forms of chronic liver disease. In all forms of chronic liver disease periostitis commonly occurs in the absence of finger clubbing. Marked tenderness over the distal leg bones is a reliable sign of underlying periostitis, but this sign is present in only a third of affected patients. This study indicates that periostitis affecting the lower leg bones is common in patients with chronic liver disease, and its presence should be sought whether or not the patient has finger clubbing.

Finger clubbing is a well-recognised sign of chronic liver disease, especially primary biliary cirrhosis (PBC) and chronic active hepatitis (CAH). ${ }^{1}$ The association of finger clubbing and periostitis has been reported in PBC, and, more rarely, in other forms of chronic liver disease, and the syndrome of hypertrophic hepatic osteoarthropathy should be considered in the differential diagnosis of bone and joint pain in patients with chronic liver disease. ${ }^{2}$

The prevalence of periostitis in PBC and other forms of chronic liver disease is unknown. It has been suggested that periostitis should be sought in patients with finger clubbing and skeletal symptoms, ${ }^{2}$ but this assumes that periostitis occurs only in the presence of finger clubbing. The aim of this prospective study was to determine the prevalence of periostitis in PBC and other forms of chronic liver disease, and to define the relationship between periostitis and finger clubbing.

Received for publication 30 September 1980.

\section{Methods}

One hundred and twenty-eight consecutive patients with biopsy-proven chronic liver disease have been studied, including 74 with PBC, and 54 with other forms of chronic liver disease (Table 1). All the patients were attending routine outpatient clinics, and possible intrathoracic causes of clubbing and periostitis were excluded by routine chest radiology. Skeletal symptoms (bone and joint pain) and signs (bone tenderness and arthritis) were recorded and finger clubbing was judged to be present when obvious loss of the angle between the nail and the nail bed was associated with sponginess of the nail bed. ${ }^{3}$ When the clinical evaluation of clubbing was equivocal, the angle between the nail and nail bed was measured using a shadowgraph similar to that described by Bentley et al. ${ }^{4}$ (Fig. 1). To establish a normal range for the nail-nail bed angle, this angle was measured in 75 healthy controls, and clubbing was diagnosed when the nail-nail bed angle was greater than 1.65 standard deviations from the 
Table 1 Patients studied, sex, mean age, and age range (years), and diseases included in mixed group

\begin{tabular}{|c|c|c|c|c|c|}
\hline \multirow[t]{2}{*}{ Disease } & \multirow[t]{2}{*}{ No. } & \multirow[t]{2}{*}{ Female } & \multirow[t]{2}{*}{ Male } & \multicolumn{2}{|c|}{ Age $(y r)$} \\
\hline & & & & Mean & Range \\
\hline $\begin{array}{l}\text { Primary biliary cirrhosis } \\
\text { Chronic active hepatitis } \\
\text { Mixed liver diseases (MLD) } \\
\text { Budd Chiari } \\
\text { Alcoholic cirrhosis } \\
\text { Sclerosing cholangitis } \\
\text { Cryptogenic cirrhosis } \\
\text { Haemochromatosis } \\
2^{\circ} \text { biliary cirrhosis } \\
\text { Sarcoidosis } \\
\text { Hepatic fibrosis }\end{array}$ & $\begin{array}{r}74 \\
24 \\
30 \\
2 \\
12 \\
5 \\
4 \\
2 \\
2 \\
1 \\
2\end{array}$ & $\begin{array}{l}70 \\
19 \\
20\end{array}$ & $\begin{array}{r}4 \\
5 \\
10\end{array}$ & $\begin{array}{l}54 \\
46 \\
56\end{array}$ & $\begin{array}{l}38-71 \\
19-61 \\
33-72\end{array}$ \\
\hline
\end{tabular}

normal $(95 \%$ confidence limit using a one-sided normal distribution).

In liver disease, periostitis first affects the distal tibiae and fibulae and, for screening purposes, affected patients can be detected by performing an anteroposterior radiograph of the distal lower leg and forearm bones. ${ }^{2}$ The radiologist evaluated the radiographs without prior knowledge of the clinical details. Periostitis was classified as 'minimal' when the periosteal rise was seen only on close inspection of the radiograph using bright lamp illumination (Fig. 2a). Periostitis was classified as 'obvious' when the periosteal thickening and rise was readily identified against a normally illuminated $x$-ray screen (Fig. 2b), and 'florid' when there was subperiosteal calcification and fusion with the outer margin of the bony cortex (Fig. 2c). Patients excluded from the study were those with unilateral periostitis, longstanding pedal oedema, and those in whom severe varicose veins or phlebitis may have stimulated a periosteal reaction.

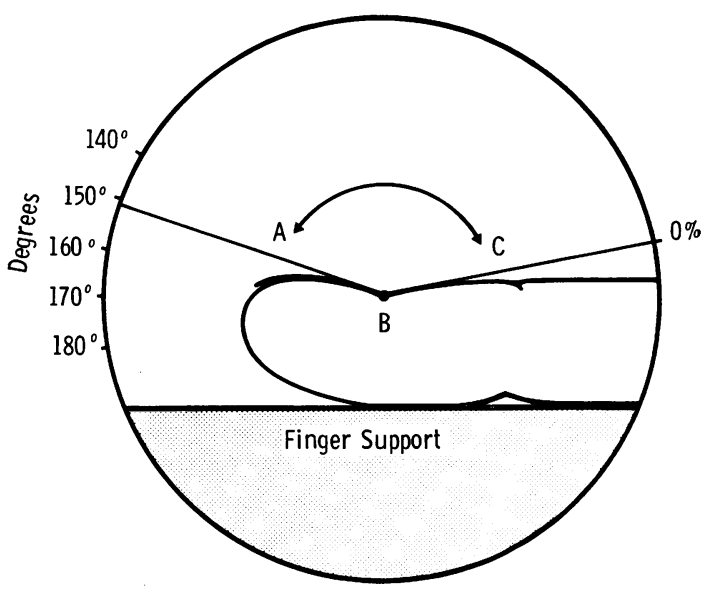

Fig. 1 Representation of the shadowgraph used for measuring the nail-nail bed angle $(A B C)$ in patients with equivocal clinical clubbing (clubbing $=A B C>168^{\circ}$ ).

\section{Results}

Obvious clubbing was present in $19 \%$ of patients with $\mathrm{PBC}, 21 \%$ with $\mathrm{CAH}$, and $17 \%$ of patients in the group of mixed liver diseases. Eleven patients were judged to have borderline clubbing, and, of these, five had nail-nail bed angles greater than $168^{\circ}$ (normal mean $\pm \mathrm{SD}=155^{\circ} \pm 8^{\circ}$ ). Therefore, using the shadowgraph to differentiate patients with equivocal clinical clubbing, the overall prevalence of clubbing was $24 \%$ in $\mathrm{PBC}, 29 \%$ in $\mathrm{CAH}$, and $23 \%$ in the group of mixed liver diseases (Table 2).

Symmetrical periostitis affecting the lower leg bones was present in $35 \%$ of patients with PBC, $29 \%$ with $\mathrm{CAH}$, and $40 \%$ with other forms of liver disease. The unexpectedly high prevalence of periostitis in the latter group is largely accounted for by the high prevalence in alcoholic cirrhosis (seven of 12 patients). Only eight patients $(6 \%)$ had periostitis affecting the distal radii and ulnae, and forearm involvement occurred only in the presence of leg bone involvement. The tibiae and fibulae were affected either singly, or together (Table 3). The periostitis was classified at minimal in $26 \%$, obvious in $45 \%$, and florid in $29 \%$ of affected patients.

The association of clubbing and periostitis is summarised in Table 2. Clubbing and periostitis occurred together in $20.2 \%$ of patients with PBC, $4.1 \%$ with $\mathrm{CAH}$, and $6.8 \%$ in the group with mixed liver diseases. Whereas in PBC $83.3 \%$ of clubbed patients had periostitis, only $14.2 \%$ of clubbed CAH patients and $28.5 \%$ of clubbed patients in the group with mixed liver diseases had periostitis. The presence of finger clubbing was significantly associated with periostitis in PBC $\left(\chi^{2}=24.25, \mathrm{P}<0.001\right)$, but not in other forms of chronic liver disease.

In all forms of liver disease, periostitis may be present without associated clubbing. Forty-two per cent of PBC patients with periostitis did not have clubbing, and the corresponding figures for $\mathrm{CAH}$ and miscellaneous liver disease were $85 \%$ and $83 \%$ respectively. 

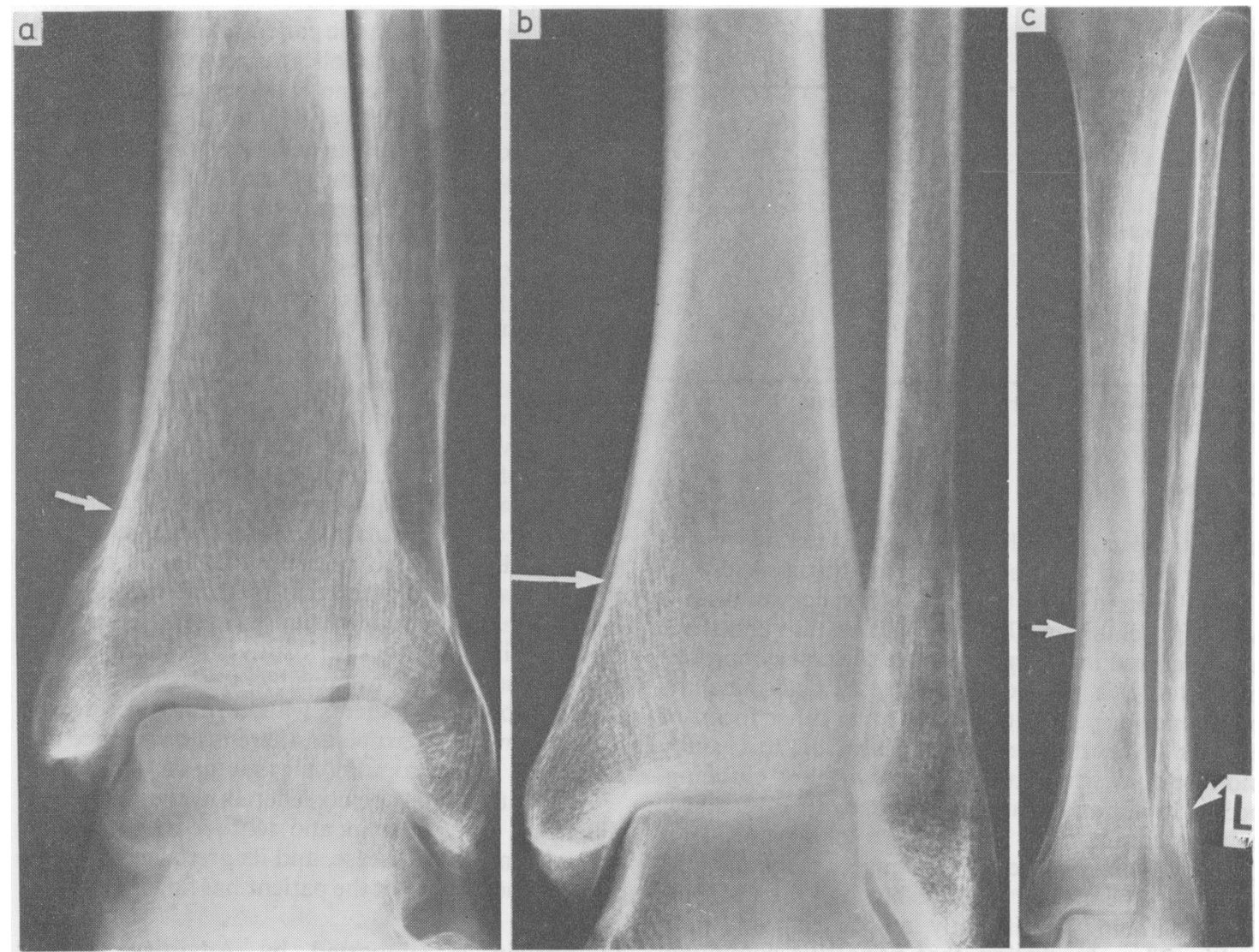

Fig. 2 Radiological appearance of (a) minimal, (b) obvious, and (c) florid periostitis affecting the tibia and fibula.

Twenty-three of the patients studied complained of arthralgia, and five had rheumatoid arthritis. Joint pains were not more common in patients with periostitis than those without periostitis. Bone pain and tenderness are common symptoms in chronic liver disease, and may be due to osteoporosis, osteomalacia, or periostitis. Marked tenderness over the lower tibiae and fibulae was present in 15 of $45(33 \%)$ patients with periostitis and only five of
$83(6 \%)$ without periostitis $\left(\chi^{2}=14.50 \quad \mathrm{P}<0.001\right)$. When present, this sign was a reliable sign of periostitis.

There was no association between the duration of illness and the extent or severity of the periostitis or clubbing, nor was there a correlation with the degree of liver dysfunction judged biochemically. In PBC, periostitis with or without clubbing occurred both in the precirrhotic and cirrhotic phase of the disease.

Table 2 Prevalence of clubbing and periostitis in PBC,CAH, and mixed liver diseases (MLD), and relationship between clubbing and periostitis in each group.

\begin{tabular}{|c|c|c|c|c|c|c|c|c|c|c|c|}
\hline & \multirow{2}{*}{$\begin{array}{l}\text { Patients } \\
\text { (No.) }\end{array}$} & \multicolumn{2}{|c|}{ Total clubbed } & \multicolumn{2}{|c|}{ Total periostitis } & \multicolumn{2}{|c|}{$\begin{array}{l}\text { Clubbing without } \\
\text { periostitis }\end{array}$} & \multicolumn{2}{|c|}{$\begin{array}{l}\text { Periostitis without } \\
\text { clubbing }\end{array}$} & \multicolumn{2}{|c|}{$\begin{array}{l}\text { Clubbing with } \\
\text { periostitis }\end{array}$} \\
\hline & & (No.) & $(\%)$ & (No.) & $(\%)$ & (No.) & $(\%)$ & (No.) & $(\%)$ & (No.) & $(\%)$ \\
\hline $\begin{array}{l}\text { PBC } \\
\text { CAH } \\
\text { MLD } \\
\text { Total }\end{array}$ & $\begin{array}{r}74 \\
24 \\
30 \\
128\end{array}$ & $\begin{array}{r}18 \\
7 \\
7 \\
32\end{array}$ & $\begin{array}{l}24 \\
29 \\
23 \\
25\end{array}$ & $\begin{array}{r}26 \\
7 \\
12 \\
45\end{array}$ & $\begin{array}{l}35 \\
29 \\
40 \\
35\end{array}$ & $\begin{array}{r}3 \\
6 \\
5 \\
14\end{array}$ & $\begin{array}{r}4 \\
25 \\
16 \\
11\end{array}$ & $\begin{array}{r}11 \\
6 \\
10 \\
27\end{array}$ & $\begin{array}{l}15 \\
25 \\
33 \\
21\end{array}$ & $\begin{array}{r}15 \\
1 \\
2 \\
18\end{array}$ & $\begin{array}{r}20 \\
4 \\
7 \\
14\end{array}$ \\
\hline
\end{tabular}


Table 3 Bone distribution of periostitis in patients with chronic liver disease*

\begin{tabular}{lll}
\hline \multirow{2}{*}{ Bones } & \multicolumn{2}{l}{ Affected patients } \\
\cline { 2 - 3 } & $($ No. $)$ & $(\%)$ \\
\hline Tibiae & 17 & 13 \\
Fibulae & 14 & 11 \\
Tibiae and fibulae & 14 & 11 \\
Total & 45 & 35 \\
& & \\
Radii & 4 & 3 \\
Ulnae & 0 & 0 \\
Radii and ulnae & 4 & 3 \\
Total & 8 & 6 \\
\hline
\end{tabular}

* Results expressed as number of affected patients. Total number of patients studied: 128.

\section{Discussion}

In a retrospective study, we suggested that periostitis be considered in the differential diagnosis of the skeletal pain in the patients with chronic liver disease and finger clubbing. ${ }^{2}$ The observation that periostitis also occurred in patients with no skeletal symptoms ${ }^{2}$ prompted this prospective study to determine the prevalence of periostitis in PBC, and other forms of chronic liver disease. The results of this study indicate that periostitis, with or without clubbing, occurs in about a third of patients with PBC and is equally common in other forms of chronic liver disease. The prevalence of finger clubbing was similar in the groups studied, but only in PBC was finger clubbing significantly associated with periostitis. The observation that periostitis commonly occurs in the absence of finger clubbing indicates that the two conditions should be sought independently, and our original conclusion-that for screening purposes periostitis should be sought in patients with finger clubbing - is invalid.

In the majority of patients the periostitis affected only the leg bones. The periostitis was unusually easy to recognise on a plain anteroposterior radiograph of the tibiae and fibulae, but 'minimal' periostitis was often only diagnosed when the radiograph was examined over a bright light.

An unexpected finding was the high prevalence of periostitis in patients with alcohol-induced cirrhosis. This study did not include patients with alcoholinduced fatty liver, fibrosis, or alcoholic hepatitis, nor did it include alcoholic patients without cirrhosis. A study of these alcoholic subgroups is presently under way to determine whether periostitis and clubbing is associated only with alcohol-induced cirrhosis, or whether it is an association of chronic alcohol ingestion, with or without liver injury.

Joint pain was not more common in patients with periostitis than those without. Marked tenderness over the lower leg bones was a distinctive sign in a third of patients with periostitis, and probably reflects inflammation of the pain-sensitive periosteum.

The results of this study indicate that periostitis is a common complication of PBC and other forms of chronic liver disease, and it is often present in the absence of finger clubbing. The presence of finger clubbing and skeletal symptoms usually alerts the clinician to the possibility of associated periostitis. Only in $\mathrm{PBC}$ is the presence of finger clubbing strongly associated with periostitis, and this observation probably explains the incorrect impression from the literature that periostitis is most common in PBC. ${ }^{2}$ The factors responsible for periostitis and finger clubbing in patients with chronic liver disease are unknown. In particular, there is no evidence that hormonal or cardiopulmonary factors are involved. ${ }^{2}$

Periostitis should be considered in the differential diagnosis of bone pain and tenderness in patients with chronic liver disease, and its presence should be sought whether or not the patient has finger clubbing.

O Epstein is supported by Advisory Services (Clinical and General) Ltd, and Mr A Chester Beatty.

\section{References}

${ }^{1}$ Whelton MJ. Arthropathy and liver disease. $B r J$ Hosp Med 1970; 3: 343-7.

${ }^{2}$ Epstein O, Ajdukiewicz AB, Dick R, Sherlock S. Hypertrophic hepatic osteoarthropathy. Clinical, roentgenologic, biochemical, hormonal and cardiorespiratory studies and review of the literature. Am J Med 1979; 67: 88-97.

${ }^{3}$ Pyke DA. Clinical assessment of clubbing. Lancet 1954; 2: $352-4$.

${ }^{4}$ Bentley D, Cline J. Estimation of clubbing by analysis of the shadowgraph. Br Med J 1970; 3: 43. 